\title{
O Hospital Aristides Maltez e o controle do câncer do colo do útero no Brasil
}

\author{
Vanessa Lana $(*)$ \\ (*) Casa de Oswaldo Cruz / Fiocruz, Rio de Janeiro. \\ vanlana@uol.com.br
}

Dynamis

[0211-9536] 2014; $34(1): 25-47$

http://dx.doi.org/10.4321/S0211-95362014000100003
Fecha de recepción: 23 de agosto de 2012

Fecha de aceptación: 17 de julio de 2013

SUMÁRIO: 1.-Introdução. 2-A Liga Baiana Contra o Câncer e o Hospital Aristides Maltez. 3-O câncer em Salvador e o atendimento no Hospital Aristides Maltez. 4.-A construção do conhecimento e divulgação científica no Hospital Aristides Maltez: educação e informação na luta contra o câncer. 5.-O Hospital Aristides Maltez e a prevenção do câncer do colo do útero no interior baiano. 6.-Jornada Brasileira de Cancerologia. 7.-Considerações finais.

RESUMO: O Hospital Aristides Maltez (HAM) foi inaugurado em 1952 na cidade de Salvador (Bahia). O hospital era uma instituição filantrópica pertencente à Liga Baiana Contra o Câncer. Centro especializado no tratamento de variados tipos de câncer, o HAM tinha sua atenção voltada prioritariamente para os cânceres femininos, principalmente o câncer do colo do útero. A instituição tornou-se referência nas ações de controle da doença na Região Nordeste do Brasil. A proposta deste artigo é analisar o processo de criação e consolidação do hospital como espaço de tratamento, pesquisa e formação profissional, avaliando seu papel na rede de discussões e ações em relação ao câncer do colo do útero formada no país em meados do século XX. A instituição foi uma das pioneiras no processo de transição na utilização de ferramentas de diagnóstico e implementação de campanhas de controle do câncer da doença em municípios interioranos.

PALABRAS CLAVE: História do câncer, câncer do colo do útero, políticas em saúde, colposcopia, citología.

KEY WORDS: History of cancer, cervical cancer, health politics, colposcopy, Pap smear. 


\section{Introdução $(*)$}

A atenção ao câncer do colo do útero no Brasil ganhou tônus a partir da década de 1940. A doença foi incorporada à agenda médica brasileira a partir do desenvolvimento de ferramentas de diagnóstico precoce e organização institucional para o controle da enfermidade. Naquele período, a detecção era uma atividade realizada principalmente em gabinetes ginecológicos de universidades, em instituições filantrópicas e em consultórios privados. Esse modelo de atenção consistia na avaliação de pacientes que iam aos consultórios por motivos diversos, com ou sem sintomas que indicassem a possibilidade de um quadro de câncer. Nestas visitas, as pacientes eram submetidas a exames para detecção de lesões no órgão. Isto ocorria principalmente porque, no país, em meados do século XX, o acesso aos serviços de saúde era limitado a uma parcela da população, geralmente àqueles que podiam pagar pelos serviços. O controle do câncer do colo do útero era visto como uma questão de detecção precoce e as ações preventivas situavam-se no acesso aos consultórios ginecológicos ${ }^{1}$.

Dos espaços de atenção à doença em meados do século XX no Brasil, o Hospital Aristides Maltez (HAM), na cidade de Salvador, Bahia, representou um exemplo de modelo de transição na utilização de ferramentas de diagnóstico, da colposcopia à citologia e implementação de campanhas de controle do câncer do colo do útero em municípios interioranos. Fruto de iniciativas filantrópicas, o Hospital tornou-se referência na região Nordeste do Brasil. Inaugurado em 1952, o HAM pertencia à Liga Baiana Contra o Câncer, instituição que tinha como lema propiciar «educação e ação na luta contra o câncer». Centro especializado no tratamento de variados tipos de câncer, o HAM tinha sua atenção voltada prioritariamente para os cânceres ginecológicos, principalmente o câncer do colo do útero, que tinha grande incidência na população local.

A proposta deste artigo é analisar o processo de criação e consolidação do HAM como espaço de tratamento, pesquisa e formação profissional, avaliando seu papel na rede de discussões e ações em relação ao câncer do colo do útero formada no país a partir da década de 1950. Esta rede

(*) Esta pesquisa foi financiada com recursos do Edital Papes/FIOCRUZ - Papes VI (APQ) Processo: 407835/2012-1.

1. Teixeira, Luiz Antônio; Löwy, Ilana. Imperfect tools for a difficult job: Colposcopy, colpocytology and screening for cervical cancer in Brazil. Social Studies of Science. 2011; 41 (1): 585-608. 
agregava espaços de pesquisa em câncer, como o Instituto de Ginecologia no Rio de Janeiro. Esses serviços protagonizaram as ações de controle e campanhas contra a doença no período, formando uma rede de intercâmbio científico, com a criação de associações corporativas, divulgação de revistas científicas, teses médicas, e estudos sobre diagnóstico, tratamento e profilaxia da enfermidade ${ }^{2}$.

A organização do HAM como espaço de controle do câncer pode ser entendida como um processo de institucionalização da cancerologia, tendo em vista a implantação, desenvolvimento e consolidação de atividades científicas num período específico. Entendemos institucionalização como o processo de construção de uma prática e discurso científicos e da organização de estratégias de ação e de grupos profissionais. Este processo requer um aglomerado de procedimentos para sua implantação, desenvolvimento e consolidação em determinados período e espaços geográficos ${ }^{3}$. Neste sentido, analisaremos o processo de institucionalização do HAM e sua consolidação como hospital de atendimento, formação profissional, implementação de tecnologias e modelos de controle em câncer ao longo das décadas de 1950 e 1960.

\section{A Liga Baiana Contra o Câncer e o Hospital Aristides Maltez}

A Liga Baiana Contra o Câncer (LBCC) foi fundada em 13 de dezembro de 1936, sob os desígnios e em seção especial da Sociedade de Ginecologia da Bahia ${ }^{4}$, com objetivo principal de propiciar «educação e ação» na luta contra o câncer. Logo após a fundação, o então interventor do Estado da Bahia, Landulpho Alves de Almeida ${ }^{5}$ estabeleceu um decreto no qual

2. Lana, Vanessa. Ferramentas, práticas e saberes: a formação de uma rede institucional para a prevenção do câncer do colo do útero no Brasil - 1936-1970 [tese de doutorado]. Rio de Janeiro: Casa de Oswaldo Cruz / Fundação Oswaldo Cruz; 2012.

3. Figueirôa, Silvia Fernanda de Mendonça. As Ciências Geológicas no Brasil: uma história social e institucional, 1875-1934. São Paulo: HUCITEC; 1997.

4. A Sociedade de Ginecologia da Bahia foi fundada em 1932, tendo o médico Aristides Maltez como seu presidente de honra.

5. Durante o primeiro governo do presidente Getúlio Vargas (1930-1945), os governadores de Estado, denominado interventores, eram designados pelo presidente como forma de manutenção de poder e da estrutura de governo. Na Bahia, o agrônomo Landulpho Alves de Almeida ocupou o posto de interventor estadual entre os anos de 1938 e 1942, no período conhecido pela historiografia como «Estado Novo». O governo de Landulpho foi marcado 
considerava a Liga como de utilidade pública, por seus ideais e trabalhos no campo da saúde pública ${ }^{6}$.

As finalidades da LBCC, estabelecidas em seu estatuto, relacionavam-se à organização de estruturas para combate ao câncer na Bahia. A instituição se propunha a propiciar elementos técnicos aos clínicos da capital e do interior para facilitar o diagnóstico precoce da doença, prestando assistência aos pacientes de forma gratuita, abrangendo tanto cuidados clínicos, quanto sociais e psicológicos. A Liga se dispunha ainda a incentivar a criação nos municípios baianos de espaços de atendimento ao paciente com câncer e organizar dados estatísticos que permitissem conhecer a situação da doença na região e os resultados obtidos com as ações empreendidas. Para manutenção de suas atividades, a LBCC contava com oito categorias de associados, que contribuíam mensalmente com os custeios das atividades ${ }^{7}$.

Em 1944, a LBCC foi incorporada à «Campanha Nacional Contra o Câncer», através de decreto presidencial ${ }^{8}$. A Campanha foi uma iniciativa do então recém-criado Serviço Nacional do Câncer, em 1942. A organização dos Serviços Nacionais de Saúde na gestão do ministro Gustavo Capanema fazia parte do grupo de estratégias do governo federal para intensificar a intervenção e normatização das ações em saúde em todo o país. Os Serviços contribuíram para o fortalecimento de uma gestão mais centralizada na saúde pública brasileira ${ }^{9}$. O movimento de formação da Campanha Nacional Contra o Câncer consistiu numa progressiva incorporação de instituições relacionadas ao câncer já em atuação em diferentes estados da federação. $\mathrm{O}$ principal objetivo da campanha era criar uma rede de controle da doença no país, a partir de instituições já existentes ${ }^{10}$.

pela ênfase no desenvolvimento agrícola dos municípios do interior baiano, na ampliação da malha rodoviária e urbanização da capital.

6. Sampaio, Consuelo Novais. 70 Anos de lutas e conquistas: Liga Bahiana Contra o Câncer. Salvador: LBCC; 2006.

7. Estatutos da Liga Bahiana Contra o Câncer. Salvador: Imprensa Oficial; 1955.

8. Decreto-Lei n. ${ }^{\circ} 6525$, de 24 de maio de 1944.

9. Fonseca, Cristina M. O. Saúde no Governo Vargas (1930-45): Dualidade institucional de um bem público. Rio de Janeiro: Editora Fiocruz; 2007; Hochman, Gilberto. Cambio político y reformas de la salud pública en Brasil. El primer gobierno Vargas (1930-1945). Dynamis. 2005; 25: 199-226.

10. Teixeira, Luiz Antônio; Fonseca, Cristina. De doença desconhecida a problema de saúde pública: o INCA e o controle do câncer no Brasil. Rio de Janeiro: Instituto Nacional do Câncer; 2007. 
Num contexto em que as ações do Ministério da Educação e Saúde no governo de Getúlio Vargas estavam voltadas para os serviços nacionais relacionadas às doenças de maior incidência, como febre amarela e malária, ao câncer a ideia era de propagandas e ações terapêuticas nos espaços hospitalares já instalados nos estados brasileiros. Assim, a incorporação de instituições à Campanha Nacional Contra o Câncer, cada uma com ações específicas e regionalizadas, foi um processo importante na construção de uma ação nacional de controle da doença. Com a vinculação à campanha, as instituições tinham acesso diferenciado a financiamentos e investimentos que possibilitavam uma ampliação em seus raios de ação ${ }^{11}$.

A principal finalidade da LBCC era a criação de um espaço para atendimento em câncer na região, um «Instituto de Câncer na Bahia». Em 1943, por ocasião da morte do médico Aristides Maltez ${ }^{12}$ e em sua homenagem, foi aprovada a construção do Instituto, que receberia o seu nome. O HAM foi inaugurado em 1952 como o órgão técnico da Liga e, dentre outros atendimentos, com atenção voltada para os cânceres que atingiam as mulheres, principalmente o câncer do colo do útero. O HAM foi o primeiro hospital especializado em câncer no norte e nordeste do país ${ }^{13}$. Em votação da Assembleia Geral da LBCC, Aristides Pereira Maltez foi nomeado presidente vitalício na LBCC, pelos trabalhos do médico com o câncer ginecológico ${ }^{14}$.

O HAM tinha como finalidade principal prestar assistência médica e social gratuita em suas enfermarias e ambulatórios ao canceroso «desvalido». Na organização financeira da instituição, 70\% dos atendimentos eram reservados para a gratuidade, enquanto os 30\% restantes ficariam disponíveis para os pensionistas. O número total de consultas da instituição aumentou consideravelmente nos primeiros anos de funcionamento. No ano de inauguração, 1952, foram registrados 582 atendimentos, cerca de

11. Teixeira; Fonseca, n. 10.

12. Aristides Maltez nasceu na cidade de Cachoeira (BA) em 31 de agosto de 1882 e faleceu em 05 de janeiro de 1943. Formou-se médico em 1908. Especializou-se em ginecologia no Hospital Presbiteriano de Nova York e, no retorno à Bahia em 1911 ocupou a cadeira de Fisiologia em sua faculdade de formação, assumiu a livre-docência em 1914 e, em 1932, a cátedra de Ginecologia na Faculdade de Medicina da Bahia. Como ginecologista, atendia em seu consultório de Partos e Moléstias das Senhoras e na enfermaria do Hospital Santa Isabel da Santa Casa de Misericórdia da Bahia. Sampaio, n. 6.

13. Sampaio, n. 6.

14. Estatutos, n. 7. 
dois pacientes atendidos por dia. Já em 1958, esse número aumentou para 15.398, representando 42 consultas diárias ${ }^{15}$.

As atividades do HAM eram mantidas, grande parte, através de donativos de empresas e famílias ricas da região. Com o progressivo aumento do interesse do governo baiano nas questões de saúde e de reorganização urbana na capital, nas primeiras décadas do século XX, novos investimentos foram direcionados para instituições filantrópicas, dentre elas a LBCC. Estes investimentos no âmbito da saúde pública tinham como objetivo fomentar a criação de uma rede de assistência em saúde no estado ${ }^{16}$. Desta rede, o HAM representava a atuação em câncer na região, para atendimento à população mais pobre e como centro de referência para controle da doença.

\section{O câncer em Salvador e o atendimento no Hospital Aristides Maltez}

Os cânceres ginecológicos ocupavam as maiores cifras nas estatísticas epidemiológicas da cidade da Salvador em meados do século XX. O câncer do colo do útero correspondia a mais de $35 \%$ dos casos no Estado da Bahia ${ }^{17}$. Entre os anos de 1957 e 1971, a doença representou 7,7\% do total de mortes ocorridas no Estado. Na década de 1960, o aumento do número de mortes pela doença cresceu mais de $30 \%$ em relação à década anterior ${ }^{18}$.

A diretriz adotada pelo HAM desde sua fundação girava em torno da ideia do diagnóstico precoce e atenção à doença em estágios o quanto antes identificados ${ }^{19}$. O ponto chave era identificar a presença de anormalidades antes do aparecimento de quaisquer sintomas e do adoecimento da paciente. $\mathrm{O}$ câncer incipiente ou assintomático era tomado como parâmetro nos objetivos de diagnóstico. Esta diretriz correspondia às ações médicas na terapêutica do câncer em meados do século XX. Como a possibilidade de cura nos estágios mais avançados do tumor era muito pequena, a organização de ações de controle tinha no diagnóstico precoce seu pilar de

\footnotetext{
15. O Câncer - Boletim de divulgação da Liga Baiana Contra o Câncer. 1962; 3 (3): 1.

16. Mota, André. Resenha - História da Saúde na Bahia: Instituições e Patrimônio Arquitetônico (1808-1958). Cadernos de Saúde Pública. 2012; 28 (5): 1005-1009.

17. Maltez Filho, Aristides. Organização de Centros e Clínicas de Diagnóstico Precoce do câncer genital. Arquivos de Oncologia. 1966; 7(1): 62-67.

18. Nunes, Fábio de Carvalho. Aspectos epidemiológicos do câncer na cidade de Salvador. Salvador: Instituto de Saúde pública; 1950.

19. Regimento Interno do Hospital Aristides Maltez. Salvador: Liga Baiana Contra o Câncer; 1965.
} 
sustentação, por permitir a estes médicos curar a doença e evidenciar seu trabalho no meio social.

Os veículos de divulgação dos trabalhos do HAM, como, por exemplo, as revistas científicas e jornais para o público em geral, destacavam a ideia do diagnóstico precoce para controle do câncer do colo do útero. Uma das principais estratégias do hospital para atrair as pacientes e conscientizar a população em geral sobre os perigos da doença era a veiculação de breves mensagens nos canais de comunicação da própria instituição ${ }^{20}$. As chamadas, endereçadas ao grande público, enfatizavam a responsabilidade individual na identificação de anormalidades e na busca pelos serviços médicos, mesmo nos casos em que não houvesse suspeitas da doença:

«Bastam duas pessoas para descobrir e vencer o câncer... Você e o médico! - 1) Faça um exame médico completo por ano... e até dois se já passou dos quarenta! - 2) Você é o primeiro a perceber "um sinal de alarme"! - 3) Não perca tempo! Procure um médico urgente! - 4) O melhor "seguro contra o câncer" é estar em dia com o exame médico» ${ }^{21}$.

No período de organização dos trabalhos do HAM, as principais ferramentas das quais dispunha a medicina para o diagnóstico do câncer do colo do útero eram a colposcopia ${ }^{22}$ de Hinselmann, a citologia ${ }^{23}$ de Papanicolaou

20. Estes veículos de comunicação da instituição serão mais bem discutidos nas próximas seções.

21. O Câncer, n. 15.

22. A colposcopia é uma técnica de exame ginecológico que permite a visualização da região do trato genital inferior (na mulher: vulva, vagina, colo e corpo uterino), através de um aparelho denominado colposcópio, que amplia e ilumina a região a ser examinada. O método permite a verificação de possíveis zonas de anormalidade, contribuiu para uma melhor compreensão da fisiopatologia da neoplasia cervical e para o diagnóstico precoce de lesões do colo. A técnica foi descrita em 1925 por Hans Hinselmann na Alemanha. Ao longo dos anos, a colposcopia evoluiu de um método de diagnóstico precoce do câncer do colo uterino para um exame mais global de todo o trato genital inferior, permitindo diagnosticar e tratar diversas patologias que atingem essa região, desde infecções virais como o HPV, passando pelas lesões precursoras e até o próprio câncer. Salgado, Clovis; Rieper, João Paulo. Colposcopia. Rio de Janeiro: FENAME - Fundação Nacional de Material Escolar / Ministério da Educação e Cultura; 1970.

23. Em 1917, Papanicolaou, a partir da análise das células presentes no esfregaço vaginal, observou a existência de fases rítmicas do ciclo sexual. Da continuidade de seus estudos, ao final dos anos 1920, verificou-se a possibilidade do reconhecimento de células cancerosas no conteúdo vaginal pela análise microscópica das células obtidas por esfregaço. Löwy, Ilana. Preventive strikes: Women, precancer, and prophylactic surgery. Baltimore: The Johns Hopkins University Press; 2010. 
e a biópsia, utilizada para confirmação de anormalidades identificadas com os dois primeiros métodos. De modo geral, o modelo de intervenção e diagnóstico utilizado no Brasil era conhecido como «modelo triplo». Este modelo, organizado e difundido pelo Instituto de Ginecologia do Rio de Janeiro, consistia na utilização conjunta das ferramentas de diagnóstico no exame de todas as pacientes, sob o argumento que o uso combinado aumentaria as certezas na identificação de anormalidades no colo uterino e catalisaria as ações de controle da doença ${ }^{24}$.

O chamado «modelo triplo» foi o dominante nas ações de controle do câncer do colo do útero no Brasil até a década de 1960. A partir deste período, a formação de campanhas de screening baseadas na utilização do Papanicolaou tornou-se uma realidade nas instituições de controle da doença no país. A colposcopia atendia às ações contra a doença no âmbito da medicina privada. No momento em que a doença começava a ser caracterizada como um problema de saúde pública, ações de maior alcance se faziam necessárias para seu controle. E para estas ações, a citologia se mostrava como método mais adequado para exames em maior escala, num alcance populacional mais amplo ${ }^{25}$.

Tendo em vista que a introdução e difusão de uma nova tecnologia estão diretamente relacionadas às prioridades e organização dos cuidados em saúde em uma dada sociedade, as prioridades na organização dos serviços de saúde a as diretrizes das políticas em saúde são guias na implementação das tecnologias médicas ${ }^{26}$. Enquanto o controle do câncer do colo do útero esteve pautado em ações mais localizadas, de atendimento ambulatorial nas faculdades de medicina, o colposcópio, em conjunto com a citologia, supria a demanda de exames e das propostas de intervenção. A partir do momento de implementação das campanhas de massa, técnicas

24. No Brasil e em outros países latino americanos como Chile e Argentina, a utilização da colposcopia como primeira ferramenta de diagnóstico do câncer do colo do útero ocorreu quase simultaneamente à difusão da tecnologia na Alemanha, num quadro diferente ao verificado na maioria dos países europeus e nos EUA. Este quadro foi identificado pela historiografia como «exceção latino-americana». Eraso, Yolanda. Migrating techniques, multiplying diagnoses: The contribution of Argentina and Brazil to early «detection policy» in cervical cancer. História, Ciências, Saúde - Manguinhos. 2010; 17 (supl. 1): 33-51.

25. Teixeira; Löwy, n. 1.

26. Brown, Nick; Webster, Andrew. New medical technologies and society: reordering life. Cambridge: Polity Press; 2004. 
mais simples, como a citologia, ganharam destaque, cabendo à colposcopia os casos já indicados como suspeitos ${ }^{27}$.

Em 1955 foram criados no HAM os Serviços de Colposcopia e de Citologia. Quando da organização destes serviços, os exames era realizados em todas as pacientes que, independente das queixas eram submetidas a uma rotina de exames como forma de prevenção do câncer do colo do útero. Conforme apontamos, nos anos iniciais do hospital, os exames eram baseados no uso conjunto das ferramentas de diagnóstico. A ação era justificada na ideia de que:

«Embora constitua ainda uma interrogação e mecanismo íntimo da carcinogênese do homem, sabe-se, hoje, que o sucesso no tratamento das lesões malignas está na precocidade de seu diagnóstico. Daí o emprego sistemático e rotineiro de duas grandes armas da Medicina na detecção do câncer do colo uterino: a Colposcopia de Hinselmann e a Citologia de Papanicolaou» ${ }^{28}$.

No início das atividades do HAM a maioria das pacientes foi diagnosticada nos estágios mais avançados de evolução do tumor. Na maioria das vezes eram realizadas apenas ações paliativas, para aliviar os sintomas e diminuir a dor. A partir da segunda metade da década de 1950, com a criação dos serviços de colposcopia e citologia e a instalação dos ambulatórios preventivos, esses números começam a sofrer uma considerável alteração. Mesmo em menor índice, alguns casos assintomáticos foram identificados. Os diagnósticos em estágios avançados, mesmo continuando altos, decaíram em relação ao quantitativo total de pacientes atendidas. Tal mudança foi contínua e acentuada ao longo da década de 1960, caracterizando as ações de controle do câncer no HAM.

As dificuldades para acompanhamento das pacientes após o diagnóstico também era uma realidade no HAM. Segundo os médicos do hospital, após a biópsia, nem todas as pacientes retornavam ao serviço. Isso era devido ao nível social das mulheres atendidas e ao fato de o câncer do colo do útero, nos primeiros estágios, não causar grandes desconfortos. Somente quando

27. Teixeira, Luiz Antonio; Porto, Marco Antonio Teixeira; Souza, Letícia Pumar Alves. A expansão do rastreio do câncer do colo do útero e a formação de citotécnicos no Brasil. Physis: Revista de Saúde Coletiva. 2012; 22 (2): 713-731.

28. Maltez, Carlos Aristides; Lima, Alberto Pereira Dias; Teixeira, Regina Stella Calmon. Câncer in situ do colo uterino - experiência do Hospital Aristides Maltez. Arquivos de Oncologia. 1965; 6 (1): 18. 
ocorriam sangramentos e corrimentos mais intensos é que as pacientes retornavam ao ambulatório para tratamento ${ }^{29}$.

As referências ao nível social das pacientes são um ponto importante, por indicarem o público principal de atendimento na instituição. Numa sociedade marcada pela desigualdade social, o câncer do colo do útero tinha um estigma de indicativo da vida sexual relacionada à promiscuidade e pobreza das mulheres. Tal fator representava um empecilho à medicina local para intervir e controlar a doença. Isto porque havia um grande tabu das mulheres em buscar o atendimento, tanto pela estigmatização quanto pelo medo do diagnóstico.

Em relação ao tratamento para as pacientes diagnosticadas com câncer do colo do útero, a cirurgia era vista como o principal método. No entanto, das pacientes diagnosticadas, apenas uma pequena parcela era submetida ao ato cirúrgico. Em um estudo realizado no período de 1958 a 1962, pela equipe do médico Carlos Aristides Maltez, foram analisados dados de 1.187 pacientes identificadas nos estágios de evolução do tumor I, II e III. Deste total, apenas 193 ou 16,9\% foram submetidas à cirurgia. Este baixo número era justificado por vários fatores. Primeiro, o reduzido número de leitos cirúrgicos de que dispunha o hospital, devido aos altos custos de instalação e manutenção destes leitos e da estadia hospitalar no pós-operatório. Segundo, ao elevado número de mulheres que eram diagnosticadas em estágios muito avançados, diminuindo a eficácia da cirurgia e agravando o risco da intervenção. E, por fim, pelas facilidades obtidas com a radioterapia, que apresentava menores custos e resultados menos invasivos. Das pacientes operadas, dez faleceram durante o período de recuperação. A sobrevida era baixa, de cerca de cinco anos pós-cirurgia. As dificuldades para acompanhamento das pacientes, a maioria proveniente do interior do Estado, eram apontadas como principal fator explicativo ${ }^{30}$.

Após a cirurgia, a técnica mais utilizada para tratamento era a radioterapia. A principal orientação para utilização da técnica era a irradiação de toda a extensão do canal cervical e de uma porção da região da vagina, de forma a atingir a maior superfície possível da região do colo uterino ${ }^{31}$.

\footnotetext{
29. Maltez; Lima; Teixeira, n. 28.

30. Alves, Hélio Eloy; Maltez, Carlos Aristides (b). Câncer do colo do útero - análise de 158 casos. Arquivos de Oncologia. 1966; 7 (2): 83-86.

31. Silveira, Agnaldo da. Câncer do colo uterino e seu tratamento pelas irradiações - primeiros resultados do Hospital Aristides Maltez. Arquivos de Oncologia, 1956; 1 (1): 7-22.
} 
A radioterapia era empregada no hospital tanto no sentido curativo quanto como medida paliativa, para atenuar as dores das pacientes, visto os estágios avançados nos quais muitos tumores eram diagnosticados.

\section{A construção do conhecimento e divulgação científica no Hospital Aristides Maltez: educação e informação na luta contra o câncer}

Para a construção e difusão do conhecimento, os membros do HAM organizaram o Centro de Estudos "Professor Aristides Maltez". O espaço debatia estudos referentes à cancerologia, uma vez por semana, contando com a presença de todos os profissionais que compunham o corpo clínico da instituição. Nas reuniões do grupo eram debatidos artigos e trabalhos acadêmicos sobre cancerologia, organizações em câncer nacionais e estrangeiras, os trabalhos efetuados e tecnologias utilizadas pelas congêneres em outras regiões do Brasil. A cada encontro eram selecionados novos materiais que embasavam as discussões e demonstram o interesse destes profissionais no diálogo com os pares. Como exemplo das atividades do Centro, no ano de 1956 foram realizadas trinta e sete sessões. Todas tinham um tema pré-determinado e leituras de referência. As reuniões eram presididas por membros do HAM e abertas a médicos de outras instituições ${ }^{32}$.

O Centro de Estudos do HAM lançou, em 1956, o periódico Arquivos de Oncologia. Em comemoração aos 20 anos de funcionamento da LBCC, o objetivo inicial da publicação era servir como veículo de divulgação dos trabalhos da instituição e homenagear os fundadores e perpetuadores das atividades da LBCC. A revista era editada pelo Centro de Estudos, e de propriedade da Liga. Dentre os intuitos destacados por seus idealizadores estavam o fortalecimento do intercâmbio científico e a divulgação de conhecimentos com as congêneres nacionais e internacionais. O periódico é uma das principais fontes de pesquisa sobre a organização, relações e atividades do HAM, os serviços em câncer na Bahia, e as articulações destes profissionais com os pares, na rede de espaços envolvidos na criação de um conjunto de ações articuladas em câncer no Brasil ${ }^{33}$.

32. Pereira Filho, Santos. Relatório das atividades do Centro de Estudos Prof. Aristides Maltez. Arquivos de Oncologia. 1956; 1 (1): 131-132.

33. Neves, Luiz de Oliveira. Os Arquivos de Oncologia. Arquivos de Oncologia. 1956; 1 (1): 5. 
Nos trabalhos da LBCC e do HAM, as campanhas educativas eram a principal ferramenta para conscientizar público e médicos da importância do diagnóstico precoce. Os Arquivos de Oncologia eram o principal veículo de divulgação destas campanhas para o público médico e sociedade em geral. Em decorrência destas campanhas, aumentava-se a demanda de atendimento e também a de pessoal qualificado para prestação de serviços. A organização das campanhas ia ao encontro dos trabalhos dos cancerologistas brasileiros de modo geral que, principalmente a partir da década de 1940, utilizaram amplamente artefatos de propaganda como artigos, cartazes, filmes - documentários, fotos, entrevistas e programas de rádio, com o intuito de informar e sensibilizar o grande público acerca da problemática do câncer. As campanhas faziam parte de uma série de estratégias que visavam evidenciar a enfermidade para o público em geral e para as autoridades governamentais e engendrar uma política nacional sólida e permanente de identificação, controle e tratamento da enfermidade ${ }^{34}$.

A organização de campanhas educativas para diagnóstico precoce do câncer foi o carro chefe das ações de controle em muitos países. Nos EUA, por exemplo, desde inícios do século XX a educação em câncer, através da veiculação de informações às mulheres, foi uma das estratégias utilizadas para diminuir a mortalidade por câncer, agregando instituições públicas, filantrópicas e sociedade civil ${ }^{35}$.

No boletim O Câncer, divulgado pela LBCC, era reservada uma breve seção para responder aos leitores o porquê de muitos dos casos de câncer que poderiam ser tratados e curados e não eram, refletindo num alto número de mortes. As explicações passavam por quatro pontos principais. Primeiro, porque ao invés de buscarem atendimento médico aos primeiros sinais de anormalidade, os pacientes recorriam a vizinhos, pais de santo, charlatães, que, na visão da Liga roubavam, enganavam e matavam. Segundo, porque o uso de remédios caseiros, banhos, e etc, ainda era mais recorrente do que os conselhos dados pelo médico, e o uso destes recursos permitia mais tempo para a doença se expandir no organismo. Em terceiro estava o medo do diagnóstico da doença, enquanto que, para os médicos, o sentimento deveria ser de alívio ao saber que, quando identificado a tempo, o câncer tinha grandes possibilidades de cura. E por fim, porque se ignorava a ideia

\footnotetext{
34. Teixeira; Fonseca, n. 10.

35. Gardner, Kirsten E. Early detection: Women, cancer, and awareness campaigns in the twentiethcentury United States. Chapel Hill: University of North Carolina Press; 2006.
} 
de que «(...) um dia perdido no tratamento do câncer significava uma ameaça à própria vida, e um convite à morte» ${ }^{36}$. Continuando as instruções, a Liga apresentava alguns «ensinamentos» que julgava básicos para o público leigo, na tentativa de quebrar o estigma da doença e atrair a população para o atendimento no Hospital:

«O câncer não é contagioso;

O medo, a ignorância e a negligência são os maiores aliados do câncer;

O câncer inicial, se não tratado a tempo, estende-se por todo o corpo tornando-se incurável;

No início, em cinco casos curam-se quatro, no fim, talvez nenhum sobre os cinco» ${ }^{37}$.

O estigma que repousavam sobre a doença, de morte anunciada, no caso do câncer do colo do útero, a identificação com a promiscuidade, e os próprios medos que envolviam a enfermidade eram um dos principais pontos combatidos pelos médicos. Em torno destas ideias, a LBCC divulgou uma série de chamadas, com instruções gerais sobre a doença, não apenas para acentuar os perigos, mas também, e principalmente, para desconstruir as imagens negativas e de repulsa em relação ao doente com câncer. $\mathrm{O}$ recurso às chamadas de impacto constantemente utilizado pela Liga nos veículos de comunicação com o público funcionavam como um alerta à população em geral e, ao mesmo tempo, como um mecanismo de divulgação da importância do atendimento realizado no HAM.

Para garantir recursos financeiros para a manutenção das atividades da instituição, e conscientizar a população sobre o câncer, eram realizadas anualmente pela LBCC em conjunto com o HAM as «Campanhas Contra o Câncer». As campanhas ocorriam em vários espaços da sociedade civil. Dentre estes espaços, o de maior destaque foi o das escolas, envolvendo alunos, professores e profissionais da educação. Entre 1956 e 1957, o foco foi com os estudantes baianos. Nos colégios do Estado foram distribuídas listas de contribuição para arrecadação de fundos para a Liga, que seriam utilizados na manutenção do HAM. Em 1958 foi lançado o movimento «O professor luta contra o câncer». A convocação envolveu professores da capital e do interior e, como resultado, recebeu contribuições de mais

36. O Câncer - Boletim de divulgação da Liga Baiana Contra o Câncer. 1959; 2 (2): 2-3.

37. O Câncer, n. 36. 
de 2000 profissionais. Todos os recursos arrecadados eram divulgados pela Liga nos periódicos acima citados e, em conjunto, eram apresentadas também as somas gastas com o atendimento no Hospital, como consultas, exames laboratoriais, colposcópicos, tratamento, dentre outras ${ }^{38}$. Como a maior fonte de recursos da Liga e, consequentemente do Hospital, era proveniente de doações da sociedade civil e dos associados, quanto mais a instituição se fizesse visível e necessária, maior seria a probabilidade de angariar recursos e manter o sistema em funcionamento.

A LBCC, juntamente com o HAM, investiu no ensino como ferramenta para o controle do câncer, formação e especialização profissional. Em 1955 lançou o primeiro curso de câncer da Bahia, que englobou no programa as seguintes especialidades: câncer ginecológico; do aparelho digestivo; do aparelho urogenital; do aparelho respiratório; dos ossos e da pele. O curso contou coma presença de nomes como Jorge de Marsillac ${ }^{39}$, João Paulo Rieper ${ }^{40}$ e Ugo Pinheiro Guimarães ${ }^{41}$. A participação destes profissionais sugere mais uma teia de diálogo com outras instâncias de pesquisa e trabalhos em câncer.

O incentivo à formação profissional estava pautado na justificativa da necessidade de um maior quantitativo de pessoal especializado para prestar atendimentos aos pacientes. A partir do ano de 1955, a Liga promoveu, anualmente, cursos de câncer para médicos já diplomados ${ }^{42}$. O objetivo dos cursos era preparar os profissionais não especializados com os conhecimentos mais atuais sobre a doença e capacitá-los a prestar atendimento aos pacientes com suspeitas da doença até o encaminhamento ao atendimento especializado. As aulas eram ministradas pelos médicos do

\footnotetext{
38. O Câncer, n. 36.

39. Graduado pela Faculdade de Medicina da Universidade do Rio de Janeiro, Jorge Sampaio de Marsillac Motta nasceu em 30 de abril de 1911, e faleceu em 2001. Foi um dos fundadores do Centro de Cancerologia em 1937 e diretor do Instituto Nacional do Câncer entre os anos 1967 e 1969.

40. João Paulo Rieper era médico do Instituto de Ginecologia do Rio de Janeiro. Foi discípulo direto de Hans Hinselman na Alemanha e responsável por introduzir a colposcopia no Brasil como ferramenta de diagnóstico do câncer do colo do útero.

41. Foi diretor geral do Instituto Nacional do Câncer nos anos 1970-1972. Nascido em 12 de março de 1901, foi diretor do Serviço Nacional do Câncer, ocasião na qual inaugurou a pedra fundamental do Inca em 1953. Entre os anos de 1959 e 1961 foi presidente da Academia Nacional de Medicina.

42. Sampaio, n. 6, p. 50-62.
} 
HAM, em parceria com profissionais de outras instituições, principalmente o Instituto de Ginecologia.

As iniciativas em formação e na utilização dos modernos recursos para controle do câncer, principalmente os femininos, levaram à inauguração, em 1973, da Escola de Citotecnologia, anexa ao HAM. A Escola tinha por finalidade a capacitação de técnicos para identificação de células cancerígenas nas lâminas levadas ao microscópio ${ }^{43}$. A orientação para organização de campanhas de diagnóstico do câncer do colo do útero em maior escala evidenciou a figura do citotécnico como profissional chave neste processo, visto que para a efetivação destas campanhas, o exame de Papanicolaou era utilizado como primeiro método de detecção ${ }^{44}$.

A partir da segunda metade dos anos 1960, o controle do câncer do colo do útero, sob influência dos programas de países como EUA e Inglaterra, passou por um processo de ampliação para a ideia de rastreamento citológico, com a realização de exames em maior escala e a formação de campanhas de prevenção da doença. Assim, a proposta inicialmente verificada na medicina brasileira, de forma geral, de transformar postos de atendimento ginecológico em centros especializados para detecção da doença, passou por alterações que atendiam à nova configuração da doença como foco da saúde pública no país. O HAM foi um dos primeiros espaços no Brasil a organizar campanhas de diagnóstico a partir destes preceitos.

A organização de curso de formação de citotécnicos evidenciava essa mudança de orientação nos trabalhos do Hospital, que caminhava com a configuração da doença dentro da saúde pública brasileira. Inicialmente utilizando o «modelo triplo» como estratégia principal de diagnóstico, o HAM, a exemplo de espaços de atendimento congêneres, conjugou colposcopia, citologia e biópsia no exame sistemático a todas as pacientes que recorriam ao serviço ambulatorial. A partir dos anos 1960, com a formação das campanhas no interior do estado, este modelo começou a ceder espaço para a utilização da citologia como primeiro exame, e, nos casos suspeitos, o direcionamento da paciente para centros de maior complexidade, como o próprio HAM, para realização dos demais exames e diagnóstico da doença ${ }^{45}$.

43. Neves, Luiz de Oliveira. Relatório do Diretor do Hospital Aristides Maltez, referente ao período de 1954 a 1957. Apresentado em sessão do Conselho Técnico da Liga Baiana Contra o Câncer em 10 de setembro de 1957. Arquivos de Oncologia. 1958; 1 (3): 50-55.

44. Teixeira; Porto; Souza, n. 27.

45. Maltez Filho, n. 17. 


\section{O Hospital Aristides Maltez e a prevenção do câncer do colo do útero no interior baiano}

A organização de centros e clínicas de prevenção e diagnóstico precoce do câncer era uma das propostas do HAM para a organização de ações de controle da doença. Os médicos da instituição defendiam a descentralização do atendimento, com o objetivo de atender um número maior de mulheres. Como espaços localizados de atuação, os ambulatórios deveriam ser supervisionados e estar em permanente contato com hospitais ou centros mais organizados. Estes espaços proporcionariam o auxílio e estrutura necessários para acompanhamento dos casos atendidos nos ambulatórios e complemento aos trabalhos ambulatoriais. Enquanto o exame colposcópico poderia ser realizado nos ambulatórios, o material citológico seria coletado e enviado para um centro devidamente montado e com profissionais treinados em análises citológicas. Além de um centro para análises em citologia, os hospitais ou centros de referência, funcionando como apoio aos ambulatórios, ainda necessitariam contar com um centro de registros dos casos considerados suspeitos, permitindo o conhecimento mais detalhado de cada caso em particular e também o retorno e acompanhamento dos mesmos. Além dos registros, tais espaços deveriam dispor de um serviço de assistência social, responsável por buscar as pacientes para retorno e acompanhar o processo de diagnóstico e tratamento, quando necessário ${ }^{46}$.

A proposta descrita acima foi o modelo implementado pelo HAM na organização de postos de atendimento no interior do estado da Bahia. As ações do hospital para o controle do câncer do colo do útero não se limitavam ao atendimento ambulatorial na cidade de Salvador. Na organização de campanhas para diagnóstico precoce da doença, um dos focos da instituição foi o trabalho de formação profissional e atendimento nos municípios do interior baiano. Esta organização tinha como base o registro de que mais de 50\% dos pacientes diagnosticados com câncer no HAM eram provenientes do interior. $\mathrm{O}$ artigo $1^{\circ}$ do regimento da $\mathrm{LBCC}$ para a realização das campanhas no interior do Estado destacava que:

«A Liga Baiana Contra o Câncer, dentro de suas disponibilidades, estabelecerá e manterá Campanhas junto aos diversos municípios do Estado da

46. Maltez Filho, n. 17. 
Bahia, visando em princípio a prevenção e detecção do câncer genital, com especial ênfase ao câncer do colo uterino» ${ }^{47}$.

As campanhas tiveram início em 1955 com a fundação do primeiro Consultório Preventivo de Combate do Câncer, na cidade de Alagoinhas. O consultório foi resultado da parceria entre a LBCC, o governo da Bahia e a prefeitura municipal de Alagoinhas. No espaço, eram realizados exames de rotina, como a citologia, sendo as lâminas para análise enviadas para Salvador. Os casos de maior gravidade já eram diretamente encaminhados ao HAM. Após a iniciativa em Alagoinhas, outras cidades receberam núcleos de controle da doença, em parceria com a Liga: Ilhéus e Itabuna em 1956, Santo Amaro e Feira de Santana em $1957^{48}$.

A criação dos consultórios seguia o modelo básico proposto pelos profissionais do HAM, de descentralização dos serviços médicos, concedendo maior autonomia aos municípios e ampliando o atendimento à população mais carente. Além deste aspecto, estes espaços também tinham a função de «desafogar» os atendimentos no HAM. Como metade dos casos do hospital era de pacientes vindos do interior, a realização dos primeiros exames e encaminhamento conforme os primeiros resultados catalisariam os trabalhos no HAM e reservaria a instituição para ações especializadas em câncer. O contato dos consultórios com o HAM deveria ser constante, tanto no que concerne à dinâmica do atendimento das pacientes, como nos relatórios de atendimento e especialização dos profissionais que atuavam no interior. Até o ano de 1958, nos cinco consultórios que haviam sido criados, o quantitativo total de atendimentos passava de 1.000. Neste período, 247 exames colposcópicos foram realizados e 23 casos de câncer diagnosticados. De todos os atendimentos, 25 foram encaminhados ao HAM em decorrência de seu estágio de evolução e/ou gravidade ${ }^{49}$. Percebemos que, com esse atendimento inicial, grande parte dos casos era resolvida no próprio interior. Com isso, o atendimento na capital era reservado aos casos de maior gravidade e os trabalhos eram agilizados em decorrência da triagem prévia que era realizadas nos postos do interior.

\footnotetext{
47. Estatutos, n. 7.

48. O Câncer, n. 36.

49. Neves, Luiz de Oliveira. Relatório do Serviço Estadual do Câncer. Arquivos de Oncologia. 1958; 1 (3): 63-67.
} 
Nas campanhas realizadas e ambulatórios instalados, o modelo de diagnóstico já seguia os preceitos de exame em maior escala, empregando a citologia como principal ferramenta. Nos casos de lâminas com resultados suspeitos, as mesmas eram encaminhadas ao HAM para novos exames e orientações sobre tratamento.

Em 1966 foi lançado um projeto piloto na cidade de Santo Amaro e a ação foi estendida para mais 15 municípios do Recôncavo Baiano entre o fim da década de 1960 e início dos anos 1970. O projeto seguia as mesmas diretrizes dos ambulatórios e tinha como objetivos ampliar a estrutura de atendimento no interior do estado. A escolha da região do Recôncavo Baiano para a execução dos primeiros projetos deveu-se ao fato de que cerca de $62 \%$ dos atendimentos do HAM até 1970 eram provenientes daquela região do Estado, que não possuía espaços para diagnóstico e tratamento da doença ${ }^{50}$.

Os trabalhos nos municípios interioranos tinham algumas diretrizes comuns. O grupo selecionado para as atividades permanecia na região por 30 dias, hospedado pela comunidade, com financiamento dividido entre a LBCC e os municípios, e mantinha o atendimento ambulatorial durante todos os dias, nos períodos da manhã e da tarde. Dentre as responsabilidades do grupo estavam: o registro das pacientes; o exame citológico e do toque vaginal, seguidos pela colposcopia e biópsia dirigida nos casos de evolução tumoral em curso; registro dos atendimentos em fichas próprias; encaminhamento dos casos de maior gravidade clínica para serviços especializados $^{51}$. Ao final da primeira fase dos trabalhos, de coleta do material de exame e seleção das pacientes com diagnóstico da doença, os casos de câncer in situ e de lesões em início de desenvolvimento eram encaminhados para internação em hospitais locais ou para o próprio HAM. Nos casos de tumores invasivos ou os quadros clínicos mais graves eram diretamente encaminhados ao HAM para tratamento especializado.

A maior parte dos recursos tanto para os exames quanto para os tratamentos era proveniente da própria LBBC. Os médicos participantes do projeto defendiam que o custo do mesmo era reduzido. E quanto maior o número de pacientes atendidas, menores os gastos com os exames ${ }^{52}$. Eram computados nos custos do programa despesas com: pessoal, locomoção e

50. Maltez, Carlos Aristides. Avaliação da experiência brasileira na prevenção do câncer cervico uterino (Em municípios do interior). Arquivos de Oncologia. 1968; 4 (1): 47-51.

51. Maltez, n. 50.

52. Maltez, n. 50. 
materiais para exame. Os gastos com laboratório de citologia e anatomia patológica não eram computados por serem estes serviços disponibilizados pelo HAM e componentes da estrutura e orçamento do hospital.

O modelo de trabalho configurado pela LBCC, através da atuação dos médicos do HAM nos municípios do interior baiano foi denominado pelos médicos do HAM de «Modelo Bahia». Na década de 1970 foi criada a «equipe de prevenção da LBCC». Esta equipe era composta por dois grupos de trabalho: o grupo de colheita e seleção e o grupo de tratamento. Antes do início do atendimento médico, era realizada uma visita na cidade a ser atendida para serem analisadas as condições de atendimento, a infraestrutura da cidade em termos de hospitais, postos de saúde e as condições de montagem de ambulatórios preventivos. Quando o município dispunha de hospitais próprios, em geral eram utilizadas as instalações e espaços dos mesmos para a montagem dos ambulatórios. Para atrair o público feminino eram distribuídos panfletos no comércio local e realizadas visitas aos domicílios divulgando e explicando o funcionamento do programa ${ }^{53}$.

$\mathrm{O}$ «Modelo Bahia» oferecia, segundo seus idealizadores, condições de aplicação em quaisquer partes do país. No entanto, alguns pontos deveriam ser observados para a implantação e sucesso do programa. No território baiano, o modelo ofereceria melhores condições de êxito quando fossem seguidas algumas instruções básicas. Primeiramente, era necessário manter um grupo permanentemente em atividade e com contato direto com as prefeituras e núcleos sociais para que fosse prestada assistência aos pacientes em exames. A seleção das pacientes se daria pela citologia, sendo seguida pela colposcopia e biópsia e, nos casos que necessitassem de tratamento especializado, o controle e acompanhamento deveriam ser constantes. O encaminhamento ao HAM deveria ser feito sempre que os centros locais não oferecessem condições de internação e nos casos mais graves. E por fim, a formação profissional, a qualificação e o incentivo aos grupos de estudos, como ocorria no Centro de Estudos do HAM fazia-se importante por garantir o envolvimento dos profissionais e a qualidade do atendimento ${ }^{54}$.

O modelo criado e difundido na Bahia pelo HAM foi um dos pioneiros na realização destas campanhas de maior alcance. Mesmo ocorrendo de 
forma regional e sem uma proposta de ação para outros estados, a iniciativa representava uma mudança no status da doença no país, que saia aos poucos do âmbito exclusivo dos hospitais especializados e gabinetes ginecológicos das faculdades de medicina. A atuação da instituição baiana foi construída de forma contemporânea e outras iniciativas no país, como em Porto Alegre e São Paulo que, mesmo organizadas de forma desconexa e sem uma proposta de diálogo ilustravam uma mudança nas diretrizes de controle do câncer do colo do útero no Brasil. A iniciativa dos médicos baianos fazia parte das estratégias de afirmação da centralidade do HAM nas ações de controle do câncer na região. Ao descentralizar a realização dos exames através da criação de ambulatórios de atendimento em municípios do interior, o HAM centralizava na instituição a leitura das lâminas coletadas e as medidas profiláticas após o diagnóstico. Assim, enquanto no início dos trabalhos a orientação era de exames com a utilização de citologia e colposcopia nas mulheres que buscassem atendimento, com a organização do «Modelo Bahia», as ações se tornaram descentralizadas e baseadas no uso do teste de Papanicolaou como técnica de diagnóstico, representando um momento de transição na orientação dos trabalhos na instituição e na própria organização das ações de controle da doença no Brasil.

\section{Jornada Brasileira de Cancerologia}

O HAM era parte integrante de um conjunto de instituições de controle do câncer do colo do útero que se formou no Brasil a partir da década de 1940, tendo como impulsionador o Instituto de Ginecologia do Rio de Janeiro. Este conjunto era formado por instituições, associações médicas, periódicos científicos e congressos médicos. Dentre os espaços de circulação destes profissionais, os congressos eram o principal lócus de interação, afirmação e divulgação dos trabalhos desenvolvidos em cada instituição ${ }^{55}$.

Como parte do processo de afirmação do HAM no controle do câncer no Brasil, entre os dias 12 e 15 de outubro de 1960 a cidade de Salvador sediou a I Jornada Brasileira de Cancerologia. O evento era uma iniciativa do HAM em conjunto com o governo do Estado da Bahia. Durante o evento foram realizadas palestras sobre o câncer em geral, estando presentes grandes

55. Lana, n. 2. 
nomes da cancerologia no Brasil. Os Arquivos de Oncologia publicaram na íntegra a cobertura da Jornada e os textos apresentados. Estiveram presentes médicos de vários estados brasileiros como Rio de Janeiro, São Paulo, Rio Grande do Sul, Alagoas, Maranhão, Ceará, Pernambuco, Pará, Minas Gerais e Rio Grande do Norte ${ }^{56}$. A jornada representava uma concretização dos trabalhos da LBCC e do HAM no controle do câncer e a projeção da instituição para além do território baiano.

Durante a realização da I Jornada de Cancerologia foi proposta a organização de um novo periódico, que compilasse os dados das publicações sobre câncer em todo o país. Tal periódico ganhou forma como a Bibliografia Brasileira de Oncologia, em 1961. O momento escolhido para apresentação da primeira versão impressa foi a II Jornada Brasileira de Cancerologia, com a previsão do lançamento de mais dois números. A proposta da publicação era preencher a lacuna correspondente à dificuldade de um levantamento bibliográfico sobre o câncer na literatura brasileira. O primeiro volume correspondia ao levantamento bibliográfico referente ao período de 1851 a 1952. O segundo abarcaria os anos de 1953 a 1960, e o terceiro, de 1961 a $1962^{57}$.

Após a I Jornada, ocorreram outras da mesma natureza. Em 1962 foi organizada a II Jornada de Cancerologia, cujo tema oficial foi a educação profissional médica para a luta contra o câncer. As Jornadas podem ser vistas como um momento de diálogo entre diferentes instituições e profissionais e de construção de diretrizes comuns nas ações de controle do câncer no Brasil. Nos discursos sobre o câncer do colo do útero, as ideias do diagnóstico precoce e a utilização da colposcopia e citologia como principais ferramentas tornaram-se uma diretriz compartilhada pelas instituições nacionais em meados do século XX. A circulação dos atores, as discussões, e publicações em periódicos evidenciam a formação de uma rede de ações em relação à doença, que colocaram a doença na agenda de saúde nacional e difundiram as tecnologias médicas de diagnóstico no país.

56. I Jornada Brasileira de Cancerologia. Arquivos de Oncologia. 1961; 4 (1): 78-82.

57. Bibliografia Brasileira de Oncologia. 1961; 1 (1): 2 . 


\section{Considerações finais}

A organização do HAM representou a solidificação da LBCC nas ações de controle do câncer do colo do útero no nordeste do país. O hospital concretizou as aspirações da Liga na criação de um espaço para tratamento e construção de conhecimento sobre a doença. Num contexto no qual a doença era culturalmente relacionada à pobreza e promiscuidade, a estratégia de controle caminhava no sentido de medicalização, deslocando o discurso das questões sociais para um cunho biológico e orgânico. Outra dificuldade era o diagnóstico, uma vez que as pacientes recorriam ao atendimento médico quando os sintomas eram aparentes, o que dificultava a intervenção e diminuía as possibilidades de cura. Neste sentido, a bandeira do diagnóstico precoce foi o grande lema dos médicos envolvidos neste projeto, baseados no argumento de quanto mais no início um tumor, ou a possibilidade do acometimento por esse, fosse identificado, melhores as expectativas no prognóstico.

No processo de difusão das ferramentas de diagnóstico do câncer do colo do útero no Brasil, o HAM foi o responsável pela introdução das tecnologias na região baiana e da formação de profissionais para utilização das técnicas. Nos primeiros anos de atividade o modelo de detecção adotado consistiu na utilização conjunta de colposcopia, citologia e biópsia, numa perspectiva de atendimento ambulatorial. Inserido no conjunto de mudanças na saúde pública brasileira, a implementação de campanhas de diagnóstico precoce no interior do estado deslocou a perspectiva para a análise em maior escala, adotando a citologia como principal estratégia de detecção, o que atendia à demanda de ampliar os atendimentos da instituição.

Além do atendimento ambulatorial, o processo de institucionalização do HAM foi marcado pelo incentivo à construção de conhecimento e formação profissional. A construção de saberes sobre a doença, assim como a divulgação de informações possibilitava maior visibilidade aos trabalhos do hospital e conferia a este um papel de centralidade e complexidade no controle do câncer do colo do útero, que extrapolava as ações de diagnóstico e terapêutica.

O hospital, assim, destacou-se por seu pioneirismo nas regiões norte e nordeste do Brasil, na articulação de ações em câncer e na implementação de modelos de atuação em relação à doença, com atendimento referencial em toda a região. Atuando numa rede de atores e espaços, o HAM manteve diálogo e intercâmbios constantes com outras instituições de atendimento 
e pesquisa em câncer em meados do século XX no Brasil e apresentou preocupação e formas de atendimento semelhantes e dialogadas com estes espaços. 